\title{
Ergin Çekirdeksizi Üzüm Çeşidinde Farklı Demir Uygulamalarının Verim ve Kalite Üzerine Etkisi ${ }^{1 *}$ \\ Tuğçe YANPAR, Semih TANGOLAR**, Melike ADA
}

$\ddot{O Z z}$

$\mathrm{Bu}$ çalışma, Mersin ili Akdeniz ilçesi Yanpar köyündeki bir üretici bağında 2019 y1lında yürütülmüştür. Çalışmada, Fe-EDDHA ((Demir-Etilendiamin-di (o-hidroksifenil asetik asit)) ve $\mathrm{FeSO}_{4}$ (Demir sülfat) gübrelerinin damlama ve enjeksiyon yöntemleri ile uygulanmasının Ergin Çekirdeksizi üzüm çeşidinde verim ve kalite üzerine etkileri incelenmiştir. Uygulamalar, $\mathrm{FeSO}_{4}$ için gözlerin kabarmasından önce, çiçeklenmeden önce ve tane tutumunda olmak üzere üç; FeEDDHA için ise çiçeklenmeden önce ve tane tutumunda olmak üzere iki farklı dönemde yapılmıştır. Sonuçta asma başına verilen miktarlar, $\mathrm{FeSO}_{4}$ bileşiğinde toplam $90 \mathrm{~g}$ ve $150 \mathrm{~g}$; FeEDDHA bileşiğinde ise toplam $60 \mathrm{~g}$ ve $100 \mathrm{~g}$ olmuştur. Çalışma sonucunda farklı $\mathrm{Fe}$ formlarının uygulanma şekli bakımından en yüksek verim ve salkım ağırlı̆̆ değerleri enjeksiyon $30 \mathrm{~g}$ uygulamasından alınmıştır. Yaprak azot konsantrasyonu üzerine Fe-EDDHA'nın, $\mathrm{FeSO}_{4}$ gübresinden daha etkili olduğu tespit edilmiştir. Demir formu ve uygulama şeklinin mikro elementler açısından sadece total ve aktif demir için önemi bulunmuş olup, demir elementi bakımından $\mathrm{Fe}$-EDDHA gübresinin $\mathrm{FeSO}_{4}$ gübresinden daha etkili olduğu belirlenmiştir. Kloroz, sadece kontrol gruplarındaki bazı yapraklarda kaydedilmiştir. Sonuç olarak, toprağa $\mathrm{FeSO}_{4}$ ve FeEDDHA formunda demir uygulanmasının üzüm verimi, salkım ağırlı̆̆ı ve tane büyüklüğü ile klorozun önlenmesinde bir miktar iyileşme sağladığ 1 görülmüştür. Daha sağlıklı öneriler için, konuyla ilgili çalışmaların sürdürülerek biriken etkinin değerlendirilmesinde yarar görülmektedir.

Anahtar kelimeler: Asma, bitki besleme, kloroz, Fe-EDDHA, demir sülfat

\section{The Effect of Different Iron Applications on Yield and Quality of Ergin Çekirdeksizi Grape Variety}

\section{ABSTRACT}

This study was conducted in a private vineyard established in Yanpar village of Mediterranean district of Mersin province in 2019 year. The effect of the dripping and the injection methods of Fe-EDDHA ((Ferrous-ethylene diamin-di (o-hydroxyphenyl acetic acid)) and $\mathrm{FeSO}_{4}$ (Ferrous sulphate) fertilizers on yield and quality of Ergin çekirdeksizi grape variety were examined. Applications for $\mathrm{FeSO}_{4}$ were done in three different periods as before bud burst, before flowering and in the berry setting; and for Fe-EDDHA, applications were carried out in two different periods as before flowering and in the berry setting. As a result, the amounts given per vine were $90 \mathrm{~g}$ and $150 \mathrm{~g}$ for $\mathrm{FeSO}_{4}$ and $60 \mathrm{~g}$ and $100 \mathrm{~g}$ for FeEDDHA. As a result of the study, in terms of iron forms application methods, the highest yield and cluster weight values of the grapes were taken from the injection $30 \mathrm{~g}$ treatment. Fe-EDDHA's effect on the nitrogen concentration of the leaves was more effective than $\mathrm{FeSO}_{4}$ fertilizer does. The effects of Fe types and application methods were significant only in total and active $\mathrm{Fe}$ element among the micro elements examined in the study and in terms of iron, Fe-EDDHA fertilizer was found more effective than $\mathrm{FeSO}_{4}$ fertilizer. Chlorosis was recorded on some of the vine leaves in the control groups. As a result, it was observed that iron application $\left(\mathrm{FeSO}_{4}\right.$ and $\left.\mathrm{FeEDDHA}\right)$ to the soil provided some improvement on grape yield, cluster weight and berry size and prevention of chlorosis. For better suggestions, it will be beneficial to continue the studies on the subject and evaluate the accumulated effect.

Keywords: Grapevine, plant nutrition, chlorosis, Fe-EDDHA, ferrous sulphate

ORCID ID (Yazar sirasina göre)

0000-0003-3941-8757, 0000-0001-7746-4258, 0000-0001-5182-0787

Yayın Kuruluna Geliş Tarihi: 07.05.2021

Kabul Tarihi: 03.12.2021

Çukurova Üniversitesi, Ziraat Fakültesi, Bahçe Bitkileri Bölümü, Adana

* Bu makale Tuğçe YANPAR'ın Yüksek Lisans tezinden üretilmiştir.

**E-posta: tangolar@cu.edu.tr 


\section{Ergin Çekirdeksizi Üzüm Çeşidinde Farklı Demir Uygulamalarının Verim ve Kalite Üzerine Etkisi}

\section{Giriş}

Dünyada 7.5 milyon ha alanda bağc1lı yapilmakta olup, toplam 77.8 milyon ton üzüm elde edilmektedir (OIV, 2019). Dünyadaki üzüm üretiminin \% 37'si Avrupa, \%34'ü Asya, $\% 19$ 'u da Amerika kıtasında yapılmaktadır. Türkiye'de ise 448000 ha alanda yapilan bağcılık tarımının, dünya toplam üzüm üretimindeki payı 3.9 milyon ton'dur. Türkiye üzüm üretiminin \%57'si sofralık, \%40'1 kurutmalık, \%2-3'ü ise şaraplık olarak değerlendirilir (OIV, 2019). Akdeniz bölgesi ülkemizde, bağ alanı ve üzüm üretimi açısından önemli bir bölge olup, diğer bölgelerle kıyaslandığında bu bakımlardan Ege bölgesinden sonra ikinci surada yer almaktadır (Söylemezoğlu ve ark., 2020).

Diğer faktörler optimumda olduğunda toprak ve bitkide yeterli besin maddelerinin bulunmas1 istenen miktarda ve kalitede üzüm üretimi için mutlak gereklidir. Birçok bitki türünde olduğu gibi (Domenico Rombolà ve ark., 2003; Akgül ve ark., 2013) asmalarda da fazla kireçli toprak koşullarında bitki besleme sorunları ile karşılaşılmaktadır (Özdemir, 2005). Kireç içeriği yüksek olan topraklarda yetiştirilen bitkilerde demir eksikliği daha çok görülür. Türkiye'deki toprakların \%26.87'sinin alınabilir demir eşiğinin altında olması (Eyüpoğlu ve ark., 1996) ve topraklardaki kireç içeriğinin fazla olması nedeniyle $\mathrm{Fe}, \mathrm{Zn}$ ve $\mathrm{Mn}$ gibi mikro besin elementlerinin yeterince alınamamas1 sonucunda bitkilerde kloroz görülmektedir (Çelik ve ark., 1998; Kaçar ve Katkat, 2007).

Akdeniz bölgesi topraklarının \%23.7' si fazla kireçli ve \%38.5' i çok fazla kireçli kategorisinde yer almaktadır (Çelik ve ark., 1998). Topraklardaki kireç oranı \%20'den fazla olan yerlerde demir noksanlığının görüldüğü bildirilmektedir. Sanchez ve ark. (2020) da demir klorozunun Akdeniz bölgesindeki üzüm üreticilerinin sık karşılaştığı bir çevresel sorun olduğunu belirtmiștir. Demir klorozu, kalsiyum karbonat yönünden zengin ve yüksek pH'lı topraklarda görülmektedir. Ayrıca bilinçsiz gübreleme, ilaçlama, aşırı sulama ve sık dikim de demir eksikliğinin diğer bazı sebepleri arasında sayılmaktadır (Aydın ve ark., 2019). Mersin ilinde yetişen erkenci üzüm çeşitleri arasında $\mathrm{Fe}$ klorozuna hassasiyet bakımından en dikkati çeken çeşitlerden birisi Ergin Cekirdeksizi'dir. Üreticilerin bu sorunun giderilmesine yönelik yoğun çaba içerisinde olduğu gözlenmekte olup, yörede ve bu çeşitte bugüne değin kloroz sorununa yönelik bilimsel bir çalışmanın yapılmaması önemli bir eksiklik olarak değerlendirilmiştir.

$\mathrm{Bu}$ çalışmanın amacı, Mersin koşullarında yetiştirilen erkenci sofralık Ergin Çekirdeksizi üzüm çeşidinde verim ve kaliteyi olumlu etkileyecek uygun demir bileşiği ve dozunu belirlemek suretiyle demir eksikliği sorununun giderilmesine katk1 sağlamak olarak ortaya konulmuştur.

\section{Materyal ve Metot Materyal}

$\mathrm{Bu}$ araştırmanın arazi çalışmaları 2019 yılında Mersin ili Akdeniz ilçesine bağlı Yanpar köyünde bir üretici bağında, pomolojik analizleri Bahçe Bitkileri Bölümü Bağcılık laboratuvarında; çalıșmanın bitki ve toprak analizleri ise Toprak Bilimi ve Bitki Besleme Bölümü Beslenme Fizyolojisi laboratuvarında yürütülmüştür. Deneme bağı deniz seviyesinden $145 \mathrm{~m}$ yükseklikte olup 36.92505 kuzey enleminde ve 34.72415 doğu boylamında yer almaktadır. Çalışmada bitkisel materyal olarak $3.5 \times 2.0 \mathrm{~m}$ mesafelerde dikili, çift kollu guyot terbiye şekli verilmiş 15 yaşındaki Ergin çekirdeksizi üzüm çeşidi, demir uygulamalarında ise Fe-EDDHA ((DemirEtilendiamin-di (o-hidroksifenil asetik asit)) (Sequestrene) ve $\mathrm{FeSO}_{4}$ (Demir sülfat) bileşikleri kullanılmıștır.

Ekim 2018-Eylül 2019 tarihleri arasında Mersin Meteoroloji Genel Müdürlüğünden alınan bazı iklim ve toprak verilerine göre; en yüksek sicaklık değeri Ağustos ayında $37.2{ }^{\circ} \mathrm{C}$; en düşük sicaklık değerleri ise Aralık ve Ocak aylarında sirasiyla $3.5{ }^{\circ} \mathrm{C}$ ve $1.2{ }^{\circ} \mathrm{C}$ olarak kaydedilmiştir. En yüksek optimum sicaklık değeri Ağustos ayında $28.7{ }^{\circ} \mathrm{C}$ olarak belirlenmiştir. Yürütülen çalışmada esas alınan 2018 Kasım-2019 Eylül tarihleri arasında toplam yağışın $536.2 \mathrm{~mm}$, toplam güneşlenme süresinin 2675.8 saat, ortalama rüzgar hızının $1.8 \mathrm{~m} / \mathrm{sn}$ ve hava oransal neminin ise ortalama

\%66.1 olduğu saptanmıştır. Deneme alanı 


\section{Ergin Çekirdeksizi Üzüm Çeşidinde Farklı Demir Uygulamalarının Verim ve Kalite Üzerine Etkisi}

toprağının $0-30 \mathrm{~cm}$ ve $30-60 \mathrm{~cm}$ toprak derinlikleri sırasıyla killi, killi tınlı bünyede, tuzsuz (\%0.04), hafif alkali ( $\mathrm{pH} 8.13$ ve 8.14), çok yüksek oranda toplam kireçli ( \%29.92 ve $\% 24.34)$ ve organik maddece fakir (\%1.73 ve $\% 1.41)$ olduğu bulunmuştur. Azotu düşük (\%0.09 ve \%0.07), fosforu orta (15.43 ppm ve 12.82 ppm), potasyumu çok yüksek ve yüksek, kalsiyum ve magnezyumu yüksek, demiri orta (3.37 ppm ve $2.75 \mathrm{ppm}$ ), bakırı yüksek ve orta (3.28 ppm ve $1.21 \mathrm{ppm})$, manganı düşük (1.41 ppm ve $1.51 \mathrm{ppm})$, çinkoyu ise orta düşük (2.11 ppm ve $0.40 \mathrm{ppm})$ seviyede içerdiği belirlenmiştir.

\section{Metot}

Çalışmada, $\mathrm{FeSO}_{4}$ ve $\mathrm{Fe}-\mathrm{EDDHA}$ olmak üzere iki demir bileşiği formu ile $30 \mathrm{~g} \mathrm{omca}^{-1}$ ve $50 \mathrm{~g}$ omca $^{-1}$ olmak üzere iki farklı uygulama dozu ve damlama ve enjeksiyon olmak üzere toprağa iki uygulama şekli kullanılmıştır. Çalışmada etkisi denenen uygulamalar; 1) $\mathrm{FeSO}_{4}$-Kontrol-Demir uygulaması yok-Su uygulaması var, 2) $\mathrm{FeSO}_{4}$ Kontrol Demir uygulaması yok-Su uygulaması yok, 3) $\mathrm{FeSO}_{4}$-damlama $30 \mathrm{~g}$, 4) $\mathrm{FeSO}_{4-}$ damlama 50g, 5) $\mathrm{FeSO}_{4}$-Enjeksiyon $30 \mathrm{~g}$, 6) $\mathrm{FeSO}_{4}$-Enjeksiyon $50 \mathrm{~g}, 7$ ) FeEDDHA-KontrolDemir uygulaması yok-Su uygulaması var, 8) FeEDDHA- Kontrol-Demir uygulaması yok-Su uygulamas1 yok, 9) FeEDDHA-damlama 30 g, 10) FeEDDHA-damlama 50 g, 11) FeEDDHAEnjeksiyon 30 g, 12) FeEDDHA-Enjeksiyon 50 g.

Demir sülfat uygulaması, gözlerin kabarmasindan önce (26 Şubat 2019), çiçeklenmeden önce (6 Mayıs 2019) ve tane tutumunda (22 Mayıs 2019) olmak üzere üç; FeEDDHA uygulaması ise çiçeklenmeden önce ve tane tutumunda olmak üzere iki kez yapılmıştır.

Gözlerin kabarmasından önceki enjeksiyon ile demir sülfat uygulamasında, asmanın taç izdüşümünde kalacak şekilde ve her bitki için iki bel derinliğinde $(30-40 \mathrm{~cm}) 4$ adet çukur açılmıştır. Açılan çukurlara 20 L' lik kovanın içerisine $30 \mathrm{~g} \mathrm{omca}^{-1}$ ve $50 \mathrm{~g} \mathrm{omca}^{-1}$ demir sülfat çözündürülüp her bir çukura $5^{\prime}$ er L olarak paylaştırılmıştır. Damlama uygulamasında ise lateral boruların, damlama kısımlarına karşı11k gelecek şekilde yaklaşık $5 \mathrm{~cm}$ derinliğinde, 40 cm genişliğinde ve $1 \mathrm{~m}$ uzunluğunda havuzlar açılmıştır. Açılan havuzlara $30 \mathrm{~g} \mathrm{omca}^{-1}$ ve $50 \mathrm{~g}$ omca $^{-1}$ gelecek şekilde demir sülfatlar, 20 L'lik suda çözündürülüp her bir asmaya verilmiştir. Çiçeklenmeden önce ve tane tutumunda Enjeksiyonla demir $\left(\mathrm{FeSO}_{4}\right.$ ve FeEDDHA) uygulaması ucu delik bir demir çubuk yardımıyla yapılmıştır. Her bir asmaya verilen suda çözündürülmüş demir sülfatın süre hesaplanması için 20 L' lik bir kova kullanılmıştır ve her bir asmaya 1.5 dakika süre belirlenmiş, bu süre her enjeksiyon için 4' e bölünmüştür. Damlama uygulaması gözlerin kabarmasından önceki uygulama şekli ile aynı biçimde yapılmıştır. Bu işlem $50 \mathrm{~g} \mathrm{omca}^{-1}$ demir sülfat ve FeEDDHA konsantrasyonları için de uygulanmıştır. Her iki demir bileşiğinin tane tutumu dönemindeki uygulamaları çiçeklenme öncesi demir uygulamasında yapıldığı şekilde tekrarlanmıştır.

Sonuçta toplamda asma başına $\mathrm{FeSO}_{4}$ demir bileşiğinden $90 \mathrm{~g}$ ve $150 \mathrm{~g}$; FeEDDHA demir bileşiğinden ise asma başına $60 \mathrm{~g}$ ve $100 \mathrm{~g}$ kullanılmıştır.

Uygulamaların etkisinin belirlenmesi amacıyla fenolojik tarihler kaydedilmiş, üzüm verimi ile salkım ağırlığı, uzunluğu ve genişliği ile 100 tane ağırlığı, pH, Suda Çözünebilir Kuru Madde (SÇKM), asitlik ve olgunluk indisi ile yaprak besin elementlerinin konsantrasyonları incelenmiş, ayrıca kloroz şiddetine bakılmıştır.

Yaprakların besin elementi analizleri için, asmaların tam çiçeklenme zamanında salkım karşısından alınan yaprakların ayaları kullanılmıştır. Önce çeşme suyu sonra saf su ve sonra \% 0.1 ' lik $\mathrm{HCl}$ çözeltisi ile daha sonra iki kez saf su ile yıkanan örnekler kese kâğıdı içerisinde $65{ }^{\circ} \mathrm{C}$ etüvde 72 saat süresince kurutulmuştur. Kurutulan örnekler agat değirmeni yardımıyla ögütülmüştür. Yaprak örneklerinde azot, Kjeldahl yöntemine göre belirlenmiştir. Toplam fosfor, vanadomolibdo fosforik asit sarı renk yöntemine göre Shimadzu model UV 1201 spektrofotometresi kullanılarak saptanmıştır (Kacar, 1972). Toplam potasyum Eppendorf Elex 6361 Fleymfotometresi kullanılarak belirlenmiştir. Yaprakların kalsiyum, magnezyum, demir, çinko ve mangan 


\section{Ergin Çekirdeksizi Üzüm Çeşidinde Farklı Demir Uygulamalarının Verim ve Kalite Üzerine Etkisi}

içerikleri, Atomik Absorpsiyon spektrofotometresi ile saptanmıştır.

Asma yapraklarında kloroz oluşumuna ilişkin incelemeler, Anonymous (1997)' e göre genç yapraklarda ve 1-5 skalası dikkate alınarak yapılmış olup; 1-Kloroz yok (koyu yeşil yaprak), 2-Az kloroz (damarlar arası açık yeşil yaprak), 3-Orta derecede kloroz (ana damarlar yeşil, damar araları sarı yaprak), 4-Şiddetli kloroz (\%10 oranından daha az nekrozların görüldüğü sarı yaprak) 5-Çok şiddetli kloroz (\%10 oranından daha fazla nekrozların görüldüğ̈̈ sarı yaprak) olarak değerlendirilmiştir.

\section{İstatistiki Analiz}

Çalışma Bölünmüş Parseller deneme desenine göre 3 tekerrürlü ve her tekerrürde 4 asma olacak şekilde yapılmıştır. Çalışmada elde edilen verilere JMP istatistik programı kullanılarak varyans analizi uygulanmış ve farklı grupların saptanmasında \%5 önem seviyesinde $\quad(p \leq 0.05) \quad$ LSD testinden yararlanılmıştır.

\section{Bulgular ve Tartışma}

Uygulamaların bitkilerin fenolojik tarihleri üzerine etkisinin önemli olmadığı, deneme alanında uyanmanın 15-18 Mart, tam çiçeklenmenin 12-13 Mayıs, ben düşmenin 2021 Haziran tarihlerinde gerçekleştiği saptanmıştır. Derim 17 Temmuz 2019 tarihinde yapılmıştır.

Çalışmada Ergin Çekirdeksizi üzüm çeşidinde demir formunun verim, salkım ağırlığı, salkım uzunluğu, salkım genişliği ve tane ağırlığına önemli bir etkisinin olmadığı görülmüştür. Uygulama şekilleri arasında en yüksek verim ve salkım ağırlığ1 değerleri (sırasıyla $6691 \mathrm{~g}$ ve $410.7 \mathrm{~g}$ ) enjeksiyon $30 \mathrm{~g}$ uygulamasindan alınmıştır (Çizelge 1). Değerlerin bu uygulamada bir miktar yüksek olmasında demir bileşiklerinin doğrudan kök bölgesine verilmesinin demir kullanımını daha etkin k1ldığ değerlendirilmektedir. Reil (1979)' e göre demir sülfat, demir kileytleri (Fe 138 ve Fe330) magnezyum sülfat, çinko sülfat, potasyum nitrat ve üre, enjeksiyon için uygun materyallerdir. Araştırıcı, enjeksiyon için en uygun zamanın ağaçların aktif gelişme göstermeye başladığı zamanlar (geç ilkbahar, yaz ve erken sonbahar) olduğunu belirtmiştir (Reil, 1979). Yürüttüğümüz çalışmada enjeksiyon uygulaması çiçeklenmeden önce ve tane tutumu olmak üzere bitkinin aktif gelişme göstermeye başladığı dönemlerde uygulanmış olup; en yüksek verim ve kalite değerleri enjeksiyon yöntemi ile elde edilmiştir. Aydın ve ark. (2019), Alaşehir'in Kemaliye bölgesinde yürüttükleri çalışmada Yuvarlak Çekirdeksiz üzüm çeşidinde 2 farklı $\mathrm{Fe}$ uygulaması yapmışlardır. Birincisinde FeEDDHA şelat gübresini asma başına 10, 20, 40, $60 \mathrm{~g}$ olarak şubat ve nisan aylarında uygulamışlardır. İkinci uygulama ise biri kontrol olmak üzere topraktan üç farklı demir formu ve dozları; $25 \mathrm{~g}$ FeEDTA omca $^{-1}$, $50 \mathrm{~g}$ FeEDDHA omca ${ }^{-1}$ ve $50 \mathrm{~g}$ $\mathrm{FeSO}_{4} 7 \mathrm{H}_{2} \mathrm{O}$ omca ${ }^{-1}$ olarak uygulanmıştır. $50 \mathrm{~g}$ $\mathrm{FeSO}_{4} 7 \mathrm{H}_{2} \mathrm{O}$ omca $^{-1}$ uygulamas1 3 Mart; $5 \mathrm{~g}$ FeEDTA omca $^{-1}$ ve 50 g FeEDDHA omca ${ }^{-1}$ uygulamaları ise 10 Nisan tarihlerinde gerçekleştirilmiştir. En yüksek verim değerlerini birinci uygulamada FeEDDHA $40 \mathrm{~g}$ omca $^{-1}$, ikinci uygulamada ise FeEDDHA $50 \mathrm{~g}$ omca $^{-1}$ uygulamasından elde etmişlerdir.

Demir formunun SÇKM, asitlik, $\mathrm{pH}$ ve olgunluk indisi üzerine istatistiksel olarak önemli bir etkisi belirlenmemiştir. Uygulama şeklinin etkisi bakımından en yüksek değerler, SÇKM, asitlik ve olgunluk indisi sırasıyla kontrol- su var (\%13.28), enjeksiyon $50 \mathrm{~g}$ (\% $0.490)$ ve kontrol su yok uygulamasinda (31.10) saptanmıştır. Demir formu x Uygulama şekli etkileşimi, SÇKM ve olgunluk indisi özelliklerinde önemli çıkmıştır (Çizelge 2). 


\section{Ergin Çekirdeksizi Üzüm Çeşidinde Farklı Demir Uygulamalarının Verim ve Kalite Üzerine Etkisi}

Çizelge 1. Demir uygulamalarının verim ve salkım özellikleri üzerine etkisi

\begin{tabular}{|c|c|c|c|c|c|}
\hline $\begin{array}{l}\text { Varyasyon } \\
\text { kaynakları }\end{array}$ & $\begin{array}{l}\text { Verim } \\
\left(\mathrm{g} \mathrm{omca}^{-1}\right)\end{array}$ & $\begin{array}{l}\text { Salkım } \\
\text { Ağgrlığ1 } \\
(\mathrm{g})\end{array}$ & $\begin{array}{l}\text { Salkım } \\
\text { Uzunluğu } \\
(\mathrm{cm})\end{array}$ & $\begin{array}{l}\text { Salkım } \\
\text { Genişliği } \\
(\mathrm{cm})\end{array}$ & $\begin{array}{l}100 \text { Tane } \\
\text { Ağgrliğ1 } \\
(\mathrm{g})\end{array}$ \\
\hline \multicolumn{6}{|l|}{ Fe bileşiği formu } \\
\hline $\mathrm{FeSO}_{4}$ & 6124 & 375.6 & 19.81 & 13.44 & 213.6 \\
\hline FeEDDHA & 6135 & 376.7 & 19.01 & 13.23 & 225.9 \\
\hline LSD $\% 5$ & Ö.D. & Ö.D & Ö.D. & Ö.D. & Ö.D. \\
\hline \multicolumn{6}{|l|}{$\begin{array}{l}\text { Uygulama şekli } \\
\text { ve dozu }\end{array}$} \\
\hline Kontrol su yok & $5753 b^{x}$ & $350.8 \mathrm{~b}$ & $18.30 \mathrm{~b}$ & 13.48 & 211.5 \\
\hline Kontrol su var & $6160 \mathrm{ab}$ & $379.2 \mathrm{ab}$ & $19.43 \mathrm{ab}$ & 13.35 & 217.2 \\
\hline Damlama $30 \mathrm{~g}$ & $6126 \mathrm{ab}$ & $373.8 \mathrm{ab}$ & $19.92 \mathrm{ab}$ & 12.99 & 220.4 \\
\hline Damlama $50 \mathrm{~g}$ & $6413 \mathrm{ab}$ & $393.9 \mathrm{ab}$ & $19.32 \mathrm{ab}$ & 13.43 & 225.8 \\
\hline Enjeksiyon $30 \mathrm{~g}$ & $6691 \mathrm{a}$ & $410.7 \mathrm{a}$ & $18.84 \mathrm{~b}$ & 13.65 & 216.4 \\
\hline Enjeksiyon $50 \mathrm{~g}$ & $5637 \mathrm{~b}$ & $348.6 \mathrm{~b}$ & $20.64 \mathrm{a}$ & 13.13 & 226.9 \\
\hline LSD $\% 5$ & 843 & 54.2 & 1.63 & Ö.D. & Ö.D. \\
\hline \multicolumn{6}{|l|}{ Interaksiyon } \\
\hline LSD \%5 & Ö.D. & Ö.D. & Ö.D. & 1.79 & Ö.D. \\
\hline
\end{tabular}

${ }^{\mathrm{x}}$ Aynı sütunda farklı harflerle gösterilen uygulamalar arasında istatistiki düzeyde önemli farklılık bulunmaktadır $(\mathrm{P} \leq 0.05)$. Ö.D.: Önemli Değil

Çizelge 2. Demir uygulamalarının şıra özellikleri üzerine etkisi

\begin{tabular}{|c|c|c|c|c|}
\hline $\begin{array}{l}\text { Varyasyon } \\
\text { kaynaklar1 }\end{array}$ & $\begin{array}{l}\text { SÇKM } \\
(\%)\end{array}$ & $\begin{array}{l}\text { Asitlik } \\
\left(\mathrm{g} 100 \mathrm{~mL}^{-1}\right)\end{array}$ & $\mathrm{pH}$ & $\begin{array}{l}\text { Olgunluk } \\
\text { İndisi }\end{array}$ \\
\hline \multicolumn{5}{|l|}{ Fe bileşiği formu } \\
\hline $\mathrm{FeSO}_{4}$ & 12.93 & 0.463 & 3.31 & 28.44 \\
\hline FeEDDHA & 12.99 & 0.465 & 3.32 & 28.24 \\
\hline LSD $\% 5$ & Ö.D. & Ö.D. & Ö.D. & Ö.D. \\
\hline \multicolumn{5}{|l|}{$\begin{array}{l}\text { Uygulama şekli ve } \\
\text { dozu }\end{array}$} \\
\hline Kontrol su yok & $13.17 \mathrm{ab}^{\mathrm{x}}$ & $0.430 \mathrm{~b}$ & 3.36 & $31.10 \mathrm{a}$ \\
\hline Kontrol su var & $13.28 \mathrm{a}$ & $0.447 \mathrm{ab}$ & 3.34 & $30.40 \mathrm{ab}$ \\
\hline Damlama $30 \mathrm{~g}$ & $12.98 \mathrm{ab}$ & $0.481 \mathrm{ab}$ & 3.28 & $27.10 \mathrm{ab}$ \\
\hline Damlama $50 \mathrm{~g}$ & $13.02 \mathrm{ab}$ & $0.453 \mathrm{ab}$ & 3.32 & $28.98 \mathrm{ab}$ \\
\hline Enjeksiyon $30 \mathrm{~g}$ & $12.60 \mathrm{~b}$ & $0.476 \mathrm{ab}$ & 3.30 & $26.88 \mathrm{ab}$ \\
\hline Enjeksiyon $50 \mathrm{~g}$ & $12.70 \mathrm{ab}$ & $0.490 \mathrm{a}$ & 3.29 & $25.97 \mathrm{~b}$ \\
\hline LSD \%5 & 0.65 & 0.052 & Ö.D. & 4.85 \\
\hline \multicolumn{5}{|l|}{ Interaksiyon } \\
\hline LSD $\% 5$ & 0.92 & Ö.D. & Ö.D. & 6.85 \\
\hline
\end{tabular}

${ }^{\mathrm{x} A y n}$ sütunda farklı harflerle gösterilen uygulamalar arasında istatistiki düzeyde önemli farklılık bulunmaktadır ( $\mathrm{P} \leq 0.05)$. Ö.D.: Önemli Değil. 


\section{Ergin Çekirdeksizi Üzüm Çeşidinde Farklı Demir Uygulamalarının Verim ve Kalite Üzerine Etkisi}

Çalışmamızda demir uygulama şeklinin, azot ve demir dişında yapraklardaki diğer makro ve mikro besin elementlerinin miktar ve oranlarına önemli bir etkisinin olmadığı belirlenmiştir (Çizelge 3 ve 4). Ayrıca, yapraklardaki azot ve demir miktarında FeEDDHA gübresinin $\mathrm{FeSO}_{4}$ gübresinden daha etkili olduğu saptanmıştır. Özbek ve Konak (2017), enjeksiyon yöntemiyle gübre uygulamalarından olumlu sonuçların elde edilebileceğini bildirmiştir. Araştırıcılar, sıvı ahır gübresini enjeksiyon yöntemi ile toprağa uyguladıkları çalışmada azot kaybının \%4.711.9 arasında azaldığını belirlemişlerdir. Bizim yürüttüğümüz çalışmada da yapraktaki en yüksek N oranı FeEDDHA demir gübresinden elde edilmiștir. Bunun, bitkilerin şelat formundaki gübreleri topraktan daha kolay alması nedeniyle yapraktaki azot miktarının artmasından kaynaklandığı düşünülmektedir. Kaptan ve Sarı (2019)' ya göre; mikro besin elementlerinin eksiklikleri verim ve kaliteyi en az makro besin elementlerinin eksikliği kadar etkilemektedir. Araştırıcılar, şelatlı gübrelerin bitkilerdeki mikro besin elementi eksikliklerinin giderilmesinde etkili olduğunu belirtmişlerdir. Akgül ve Uçgun (2010), Isparta Senirkent bölgesinde farklı demir gübrelerinin şeftalide demir ve diğer besin elementlerinin alımına yönelik yaptıkları çalışmada FeEDDHA o-o 3, 6, FeEDDHA o-o 4,8, $\mathrm{FeSO}_{4}$, FeDTPA ve FeEDTA demir gübrelerini kullanmıştır. Çalışma sonucundan elde edilen bulgulara göre yapraklardaki en yüksek demir miktarı FeEDDHA gübrelerinden elde edilmiştir. $\mathrm{N}, \mathrm{P}, \mathrm{Cu}, \mathrm{Zn}$ ve $\mathrm{Mn}$ besin elementlerinin alımında demir gübrelerinin arasında bir fark bulunmadığı tespit edilmiştir.

Deneme alanında kloroz belirtisi yalnızca kontrol grubuna ait bazı asmalarda görülmüş olup yapraklardaki kloroz derecesine 2-3 skala değeri verilmiștir. Belirtilen skala derecesine sahip yaprakların \%4-6 oranında olduğu hesaplanmıştır (Çizelge 5). Demir uygulaması yapılan asmalarda kloroz gözlenmemiştir. Özdemir (2005)' in Yalova İncisi, $140 \mathrm{Ru}$ ve $1103 \mathrm{P}$ genotiplerinin farklı kireç içeriklerine sahip topraklarda $(\% 10,30$ ve 50) demir klorozuna etkilerini belirlemeye çalıştığ çalışmasında 20 ppm FeEDDHA, 20 ppm $\mathrm{FeSO}_{4}+$ Çiftlik gübresi $\left(100 \mathrm{~g} \mathrm{saks}^{-1} / 5 \mathrm{~kg}\right.$ toprak ${ }^{-1}$ ), 20 pmm $\mathrm{FeSO}_{4}+$ Sitrik asit ve kontrol (Fe uygulaması yok) uygulamalarını yapmıştır. Çalışma sonucuna göre kireç miktarı arttıkça yapraklarda görülen klorozun da arttığını ancak klorofil konsantrasyonunun azaldığını tespit etmiştir. Çalışmada belirtilen bu sonuçlar, kloroza hassas olduğu, yetiştirildiği erkenci üzüm bölgesinde de gözlenen çalışma materyalimiz Ergin Çekirdeksizi çeşidinde 0-30 $\mathrm{cm}$ ve $30-60 \mathrm{~cm}$ sirasiyla $\% 29.92$ ve $\% 24.34$ toplam kireç içeriğine sahip deneme alanı toprağ 1 için normal bir durum olarak değerlendirilmiştir. Yılmaz ve Yildız (2001), demir klorozuna dayanıklı Tufts çeşidi ile hassas olan Chandler ve Selva çilek çeşitlerinde topraktan ve yapraktan demir gübrelerinin verim ve besin maddesi içeriğini araştırdıkları çalışmalarında bitkilerde demir klorozu görülmediğini ve verimin olumlu yönde etkilendiğini belirtmişlerdir.

\section{Sonuç ve Öneriler}

$\mathrm{Bu}$ çalışma ile Mersin ili koşullarında yetiştirilen ve yer yer demir klorozuna hassas olduğu gözlenen Ergin Çekirdeksizi üzüm çeşidinde bu sorunun giderilmesi için verim ve kaliteyi olumlu etkileyecek uygun demir bileşiği ve dozunun belirlenmesi amaçlanmıştır.

Demir formunun $\left(\mathrm{FeSO}_{4}\right.$ ve $\left.\mathrm{FeEDDHA}\right)$ verim ve salkım özellikleri ile tane ağırlığı üzerine etkisi önemli olmamıştır. Demir uygulama yöntemleri arasından en yüksek üzüm verimi ve salkım ağırlı̆̆ değerleri enjeksiyon $30 \mathrm{~g}$ uygulamasından elde edilmiştir. Verim ve salkım ağırlığı değerlerinin enjeksiyon uygulama yönteminde bir miktar yüksek olması, demir bileşiklerinin doğrudan etkili kök derinliğine verilmesi yoluyla demir kullanımının bitkiler tarafından daha etkin k1lınması ile ilişkilendirilmiştir. Şıra özellikleri üzerine de demir bileşiği tipinin etkisinin önemli olmadığı saptanmış; buna karşın SÇKM, asitlik ve olgunluk indisi bakımından demir uygulama şekli önemli etkide bulunmuştur. 


\section{Ergin Çekirdeksizi Üzüm Çeşidinde Farklı Demir Uygulamalarının Verim ve Kalite Üzerine Etkisi}

\begin{tabular}{cccccc}
\multicolumn{6}{c}{ Cizelge 3. Farklı Demir Uygulamalarının Makro Elementler Üzerine Etkisi } \\
\hline Varyasyon kaynakları & $\mathrm{N}(\%)$ & $\mathrm{P}(\%)$ & $\mathrm{K}(\%)$ & $\mathrm{Ca}(\%)$ & $\mathrm{Mg}(\%)$ \\
\hline Fe bileşiği formu & & & & & \\
FeSO & $2.11 \mathrm{~b}^{\mathrm{x}}$ & 0.17 & 0.84 & 2.65 & 0.45 \\
FeEDDHA & $2.53 \mathrm{a}$ & 0.33 & 0.84 & 2.74 & 0.48 \\
LSD \%5 & 0.23 & Ö.D & Ö.D & Ö.D & Ö.D \\
Uygulama şekli ve dozu & & & & & \\
Kontrol su yok & $2.04 \mathrm{bc}$ & $0.15 \mathrm{~b}$ & $0.88 \mathrm{a}$ & $2.90 \mathrm{a}$ & $0.46 \mathrm{a}$ \\
Kontrol su var & $2.38 \mathrm{ab}$ & $0.18 \mathrm{a}$ & $0.81 \mathrm{a}$ & $2.69 \mathrm{a}$ & $0.46 \mathrm{a}$ \\
Damlama 30g & $2.40 \mathrm{ab}$ & $0.17 \mathrm{a}$ & $0.79 \mathrm{a}$ & $2.63 \mathrm{a}$ & $0.49 \mathrm{a}$ \\
Damlama 50g & $2.76 \mathrm{a}$ & $0.17 \mathrm{a}$ & $0.77 \mathrm{~b}$ & $2.71 \mathrm{a}$ & $0.50 \mathrm{a}$ \\
Enjeksiyon 30g & $1.71 \mathrm{c}$ & $0.17 \mathrm{a}$ & $0.91 \mathrm{a}$ & $2.46 \mathrm{~b}$ & $0.42 \mathrm{~b}$ \\
Enjeksiyon 50g & $2.61 \mathrm{a}$ & $0.17 \mathrm{a}$ & $0.91 \mathrm{a}$ & $2.77 \mathrm{a}$ & $0.46 \mathrm{a}$ \\
LSD \%5 & 0.39 & 0.02 & 0.13 & 0.37 & 0.06 \\
Interaksiyon & & & & & \\
LSD \%5 & 0.55 & Ö.D. & Ö.D. & Ö.D. & Ö.D. \\
\hline
\end{tabular}

\begin{tabular}{|c|c|c|c|c|}
\hline \multicolumn{5}{|c|}{ Çizelge 4. Farklı Demir Uygulamalarının Mikro Elementler Üzerine Etkisi } \\
\hline Varyasyon kaynakları & $\begin{array}{c}\mathrm{Zn} \\
(\mathrm{ppm})\end{array}$ & $\begin{array}{c}\mathrm{Mn} \\
(\mathrm{ppm})\end{array}$ & $\begin{array}{c}\mathrm{Fe} \\
(\mathrm{ppm})\end{array}$ & $\begin{array}{c}\text { Aktif Fe }^{+2} \\
(\mathrm{ppm})\end{array}$ \\
\hline \multicolumn{5}{|l|}{ Fe bileşiği formu } \\
\hline $\mathrm{FeSO}_{4}$ & 156.87 & 80.11 & $83.25 \mathrm{~b}$ & $31.03 \mathrm{~b}$ \\
\hline FeEDDHA & 165.91 & 68.95 & $116.00 \mathrm{a}$ & $48.15 \mathrm{a}$ \\
\hline LSD \%5 & Ö.D. & Ö.D. & 13.97 & 3.11 \\
\hline \multicolumn{5}{|l|}{ Uygulama şekli ve dozu } \\
\hline Kontrol su yok & 162.37 & $82.98 \mathrm{a}^{\mathrm{x}}$ & $87.37 \mathrm{a}$ & $29.18 \mathrm{c}$ \\
\hline Kontrol su var & 160.03 & $88.63 \mathrm{a}$ & $79.17 \mathrm{~b}$ & $27.68 \mathrm{c}$ \\
\hline Damlama $30 \mathrm{~g}$ & 158.02 & $68.42 \mathrm{a}$ & $104.26 \mathrm{a}$ & $43.06 \mathrm{~b}$ \\
\hline Damlama 50g & 159.745 & $69.80 \mathrm{a}$ & $109.82 \mathrm{a}$ & $56.04 \mathrm{a}$ \\
\hline Enjeksiyon 30g & 161.66 & $57.03 \mathrm{~b}$ & $109.91 \mathrm{a}$ & $42.01 \mathrm{~b}$ \\
\hline Enjeksiyon $50 \mathrm{~g}$ & 166.53 & $80.33 \mathrm{a}$ & $107.21 \mathrm{a}$ & $38.24 \mathrm{~b}$ \\
\hline LSD $\% 5$ & Ö.D. & 22.64 & 24.20 & 5.74 \\
\hline \multicolumn{5}{|l|}{ Interaksiyon } \\
\hline LSD $\% 5$ & Ö.D. & Ö.D. & 34.21 & 14.9 \\
\hline
\end{tabular}

Farklı demir uygulamalarının yaprakların makro ve mikro besin elementleri üzerine etkisi incelendiğinde demir ve azot konsantrasyonu üzerine FeEDDHA' nın $\mathrm{FeSO}_{4}$ gübresinden daha etkili olduğu belirlenmiştir. Yapraklarda kloroz belirtileri, sadece kontrol gruplarındaki bazı asmalarda dikkati çekmiş ve kaydedilmiştir.

Sonuçta, toprağa demir uygulamasının üzüm verimi ve salkım ağırlı̆̆ ile klorozun önlenmesinde bir miktar iyileşme sağladığ değerlendirilmiştir.

$\mathrm{Bu}$ çalışma sonuçları ile ilgili sağlıklı bitki besleme önerileri için, konuyla ilgili çalışmaların sürdürülerek incelenen özellikler kapsaminda biriken etkinin değerlendirilmesinde yarar görülmektedir. Sonraki çalışmalarda, Ergin Çekirdeksizi üzüm çeşidinde veya benzeri demir klorozuna hassas çeşitlerde inorganik ya da organik farklı demir 


\section{Ergin Çekirdeksizi Üzüm Çeşidinde Farklı Demir Uygulamalarının Verim ve Kalite Üzerine Etkisi}

bileşiklerinin enjeksiyon yöntemi gibi farklı uygulama metotları kullanılarak denenmesinin yararlı olacağı düşünülmektedir.

Çizelge 5. Değişik Uygulamalarda Saptanan Klorozlu Yaprakların Derecesi ve \% Miktarı

\begin{tabular}{|c|c|c|c|}
\hline \multicolumn{2}{|c|}{ Uygulamalar } & $\begin{array}{c}\text { Kloroz } \\
\text { Derecesi }\end{array}$ & $\begin{array}{c}\text { Klorozlu } \\
\text { Asma (\%) }\end{array}$ \\
\hline Kontrol & $\begin{array}{c}\mathrm{Su} \\
\text { Yok }\end{array}$ & $2-3$ & 4 \\
\hline Kontrol & $\begin{array}{c}\mathrm{Su} \\
\text { Var }\end{array}$ & $2-3$ & 6 \\
\hline
\end{tabular}

\section{Kaynaklar}

Akgül, H., Uçgun, K. (2010) Isparta (Senirkent) bölgesi topraklarında farklı demir gübrelerinin şeftalide demir ve diğer elementlerin alımına etkileri. Ege Üniv. Ziraat Fak. Dergisi, Özel Sayı: 29-35.

Akgül, H., Uçgun, K., Altındal, M. (2013) Bazı şelatlı demir gübrelerinin şeftalide demir eksikliği klorozuna etkileri. Meyve Bilimi, 1(1): 12-17.

Anonymous (1997) Descriptors for Grapevine (Vitis ssp.). International Plant Genetic Resources Institute, Rome, $58 \mathrm{p}$.

Aydın, S., Yeğenoğlu, E.D., Talas, Y. (2019) The effect of $\mathrm{Fe}$ applications in different forms and times on the yield of Round seedless grapes (Vitis vinifera L.). 6th Int. Conference on Sustainable Agric. and Environment, 41-45.

Çelik, H., Ağaoğlu, Y.S., Fidan, Y., Marasalı, B., Söylemezoğlu, G. (1998) Genel Bağcılık. Sun Fidan AŞ. Mesleki Kitaplar Serisi:1. Fersa Matbaa, Ankara, 253 s.

Domenico Rombolà, A., Toselli, M., Carpintero, J., Ammari, T., Quartieri, M., Torrent, J., Marangoni, B. (2003) Prevention of iron deficiency induced chlorosis in Kiwifruit (Actinidia deliciosa) through soil application of synthetic vivianite in a calcareous soil. $J$ of Plant Nutr 26 (10-11): 2031-2041.

Eyüpoğlu, F., Kurucu, N., Talaz, S. (1996) Türkiye topraklarının bitkiye yarayışlı bazı mikro element (Fe, $\mathrm{Zn}, \mathrm{Mn}$ ) bakımından genel durumu. Toprak Gübre Araşt. Enst. Genel Yayın No. 217, Ankara, $67 \mathrm{~s}$.

Kacar, B., Katkat, V. (2007) Bitki Besleme. Nobel yayınları, Ankara, $659 \mathrm{~s}$.

Kaptan, M. A., Sarı, H. (2019) Yapraktan farklı gübre uygulamalarının karnabahar (Brassica oleracea L.) gelişimi üzerine etkileri. Kahramanmaraş Sütçü Imam Üniv. Tarım ve Doğa Dergisi, 22(4): 512-516.

Özdemir, G. (2005) Farklı kireç içerikli topraklarda yetiştirilen asma genotiplerinde değişik uygulamaların $\mathrm{Fe}$ alımı üzerine etkilerinin morfolojik ve fizyolojik yönden incelenmesi. Doktora Tezi, Çukurova Üniv Fen Bilimleri Enst Adana, $186 \mathrm{~s}$.

Özbek, O., Konak, M. (2017) Sıv1 ahır gübresi dağıtma makinalarında farklı uygulayıciları azot kaybına etkisi. Selcuk $J$ of Agric and Food Sci 31(1): 1-10.

Reil,W. (1979) Pressure-Injecting chemicals into trees. California Agriculture, 33(6): 16-19.

Söylemezoğlu, G., Çelik, H., Kunter, B., Ünal, A., Özer, C., Kirac1, M.A., Akkurt, M., Boz, Y., Karaman, H.T. (2020) Bağcilıkta mevcut durum ve gelecek. Türkiye Ziraat Mühendisliği IX. Teknik Kongresi, Ocak 2020. Ankara, s 609-646.

Yılmaz, H., Yıldız, K. (2001) Çileklerde yapraktan ve topraktan mikro element içerikli gübre uygulamalarının verim ve kalite üzerine etkileri. Yüzüncü Yll Üniv., Ziraat Fak., Tartm Bilimleri Dergisi, 11(2): 35-39. 